INTERNATIONAL CENTER FOR
International Center for Public Policy

Working Paper 19-02

March 2019
Time-saving Goods, Time Inequalities, and Optimal Taxation

\author{
Cristian F. Sepúlveda
}

\section{(5)}

GeorgaState University
ANDREWYOUNG SCHOOL

OF POLICY STUDIES 



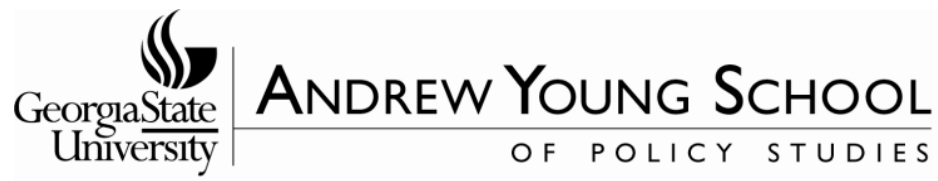

International Center for Public Policy Working Paper 19-02

\section{Time-saving Goods, Time Inequalities, and Optimal Taxation}

\author{
Cristian. F. Sepúlveda
}

\section{March}

2019

International Center for Public Policy

Andrew Young School of Policy Studies

Georgia State University

Atlanta, Georgia 30303

United States of America

Phone: (404) 413-0235

Fax: (404) 651-4449

Email: paulbenson@gsu.edu

Website: http://icepp.gsu.edu/

Copyright 2019, the Andrew Young School of Policy Studies, Georgia State University. No part of the material protected by this copyright notice may be reproduced or utilized in any form or by any means without prior written permission from the copyright owner. 


\section{$\underset{\substack{\text { Georgatsate } \\ \text { University }}}{\iint_{\text {OF POLICY STUDIES }}} \mid \frac{\text { ANDREW YOUNG SCHOOL }}{\mid}$}

\section{International Center for Public Policy Andrew Young School of Policy Studies}

The Andrew Young School of Policy Studies was established at Georgia State University with the objective of promoting excellence in the design, implementation, and evaluation of public policy. In addition to two academic departments (economics and public administration), the Andrew Young School houses seven leading research centers and policy programs, including the International Center for Public Policy.

The mission of the International Center for Public Policy (ICePP) at the Andrew Young School of Policy Studies is to provide academic and professional training, applied research, and technical assistance in support of sound public policy and sustainable economic growth in developing and transitional economies.

ICePP is recognized worldwide for its efforts in support of economic and public policy reforms through technical assistance and training around the world. This reputation has been built serving a diverse client base, including the World Bank, the U.S. Agency for International Development (USAID), the United Nations Development Programme (UNDP), finance ministries, government organizations, legislative bodies, and private sector institutions.

The success of ICePP reflects the breadth and depth of its in-house technical expertise. The Andrew Young School's faculty are leading experts in economics and public policy and have authored books, published in major academic and technical journals, and have extensive experience in designing and implementing technical assistance and training programs. Andrew Young School faculty have been active in policy reform in over 40 countries around the world. Our technical assistance strategy is not merely to provide technical prescriptions for policy reform, but to engage in a collaborative effort with host governments and donor agencies to identify and analyze the issues at hand, arrive at policy solutions, and implement reforms.

ICePP specializes in four broad policy areas:

- Fiscal policy (including tax reforms, public expenditure reviews, tax administration reform)

- Fiscal decentralization (including decentralization reforms, design of intergovernmental transfer systems, urban government finance)

- Budgeting and fiscal management (including local government budgeting, performancebased budgeting, capital budgeting, multi-year budgeting)

- Economic analysis and revenue forecasting (including micro-simulation, time series forecasting)

For more information about our technical assistance activities and training programs, please visit our website at http://icepp.gsu.edu or contact us by email at paulbenson@gsu.edu. 


\title{
Time-saving Goods, Time Inequalities, and Optimal Taxation
}

\author{
Cristian F. Sepúlveda*
}

March 2019

\begin{abstract}
Time-saving goods are defined as market goods that reduce home labor requirements (e.g. restaurants; washing machines). Assuming that time savings are costly, this paper shows that lower-income individuals can purchase fewer time savings and enjoy less leisure time. Commodity tax rates affecting low-income individuals should depend more on time savings, and less on the classic Corlett and Hague rule. The related literature suggests to impose lower tax rates on goods that require less home labor. This paper shows that goods that offer greater time savings with respect to their more affordable substitutes should also receive favorable tax treatment.
\end{abstract}

Keywords: time-saving goods, optimal taxation, home labor, home production, time allocation

JEL classification: $\mathrm{H} 21, \mathrm{D} 13, \mathrm{~J} 22$

\footnotetext{
* Department of Economics, Farmingdale State College, State University of New York| 2350 Broadhollow Road, School of Business Building, Room 200, Farmingdale, NY 11735-1021 | cristian.sepulveda@farmingdale.edu.

I am grateful to Tuomas Matikka, Richard Weber and the participants of the 71th Annual Congress of the International Institute of Public Finance. I am also very grateful to Steven Sheffrin and James Alm for their support while I worked on this manuscript as part of my postdoctoral fellowship at Tulane University.
} 


\section{Introduction}

This paper introduces the concept of time-saving goods into the theory of optimal commodity taxation and proposes an adjustment to the traditional Corlett and Hague (1953-54) rule. Provided that the time constraint is used up with market labor, leisure, and home labor, time-saving goods are here defined as market goods or services that allow the individual to reduce the time devoted to home or non-market labor, leaving more time available for incomegenerating market labor and enjoyable leisure. Based on Becker's (1965) seminal contribution, the literature has analyzed how optimal taxation results change when it is necessary to use home labor to convert market goods into (using Becker's terminology) basic commodities that are the direct source of utility. This paper shows that high-income individuals are better able to "purchase more time" through the time-saving goods available in the market, and thus systematically enjoy more leisure than low-income individuals. The resulting difference in the allocation of time between high- and low-income individuals affects the optimal tax rules and justifies the use of differential commodity taxes.

Time-allocation decisions, and particularly the choice of leisure, have traditionally been a central element of optimal tax theory. At the individual level, and given that leisure cannot be directly taxed, the well-established Corlett and Hague (1953-54) rule states that optimal tax rates should be higher for those goods that are more complementary with leisure. In the context of many taxpayers, Atkinson and Stiglitz (1976) show that if preferences for goods are weakly separable from leisure, differential commodity taxation is suboptimal. If weak separability does not hold, however, the applicability of Corlett and Hague rule can be extended to the multiperson economy (Nava, Schroyen and Marchand 1996). The literature incorporating home labor 
in the derivation of optimal tax rules has built upon these results and showed that goods that are more time consuming should bear greater tax rates (Gahvari and Yang 1993; Kleven, Richter and Sorensen 2000; Kleven 2004; Boadway and Gahvari 2006). In particular, Boadway and Gahvari (2006) allow for home labor to be either a leisure-substitute, in which case consumption time has no opportunity cost because it is enjoyable (like leisure), or a labor-substitute, in which case consumption time is not enjoyable and thus faces the opportunity cost of not working. Only labor substitution creates distortions not accounted for in the traditional Corlett and Hague rule, and thus the more the time spent on home labor the greater the adjustment required on the optimal tax rate derived under that rule.

A common assumption in the literature on optimal taxation with home labor is that each basic commodity is produced with a fixed proportion of market goods and home labor. This assumption suggests that the technology available to produce a basic commodity is unique and there is only one market good available to produce it. In practice, however, there may be many market goods available to produce the same basic commodity, and these goods are most often associated with alternative production technologies requiring different amounts of home labor. For example, the basic commodity "dinner" can be produced with some market good "food" and a certain amount of home labor devoted to purchasing the food, cooking, eating, and cleaning; or alternatively, with the market good "restaurant dinner" and a likely smaller amount of home labor.

This paper takes a closer look into the production process and the consumption choices pertaining to each basic commodity. It keeps the assumption of fixed proportions between each market good and home labor, but allows for substitution among alternative market goods to produce the same basic commodity. As a result, the home labor requirement of a basic 
commodity depends on the specific market good used, which is associated with different time savings. The concept of a time-saving good encompasses not only the time required for consuming the basic commodity, but also qualitative attributes of the market good. To the extent that a qualitative attribute, added as an improvement to a market good, makes a basic commodity enjoyable - as in the case of a "nice" car or restaurant - then it allows a consumer to transform home labor into leisure (or a labor-substitute activity into a leisure-substitute activity). By definition, these cases can also be considered as time savings.

Other things equal, market goods that provide greater time savings can be expected to have a higher price. This is a key assumption made in this paper, and implies that greater time savings are available for individuals with higher incomes. Two polar opposite cases are used to illustrate the effects of time-saving goods on optimal tax rules. Individuals with sufficiently high levels of income may be able to completely eliminate home labor, such that total time available is used up with leisure and market labor, as in the traditional time allocation model without home production. In contrast, individuals with sufficiently low levels of income may be unable to purchase significant time savings, which may force them to reduce and even eliminate leisure time. The need for home labor in the production of basic commodities and the presence of costly time savings imply that income inequalities are associated with time inequalities, a concept that has not been formally described in the literature.

Costly time savings and time inequalities have important consequences for the theory of optimal taxation. Since high-income individuals are better able to reduce home labor, the traditional optimal tax rules (derived without considering home production) can be more directly applied to them. Home labor can be expected to increase as the income level is reduced, and this paper shows that in this (more general) case the Corlett and Hague rule must be accompanied 
with an additional "time-saving rule" that accounts for the level of time savings and for the marginal (negative) effects of taxes on time savings: Goods that offer greater time savings per dollar (both in average and in the margin) should be assigned a tax rate lower than the one suggested by the Corlett and Hague rule. The reason is that for any given tax burden, individual utility is higher when home labor is reduced. Moreover, in the particular low-income case with no leisure, the complementarity of market goods and leisure is no longer relevant, and only the (average) time-saving rule determines the optimal commodity tax rates.

The (average) time-saving rule is largely compatible with previous results in the literature. When time savings allow to fully eliminate home labor, consumption time can be characterized as (or it is replaced by) leisure time. The same as under the Boadway and Gahvari's (2006) framework, where this case corresponds to a scenario in which all goods are leisure-substitutes, the classical Corlett and Hague result remains as the only relevant tax rule. In contrast, the presence of home labor or goods that are labor-substitutes is generally recognized as a source of additional distortions, and the literature agrees that goods that require more home labor should be taxed more heavily. In this context, the time-saving rule qualifies previous results in Gahvari and Yang (1993), Kleven, Richter and Sorensen (2000), Kleven (2004), and Boadway and Gahvari (2006) in two ways. First, the relevance of alternative optimal tax rules depends not only on predetermined home labor requirements of basic commodities, but on the level of income. By allowing for costly time savings and for substitution among market goods in the production of a given basic commodity, a change in the level of income is shown to affect the amount of home labor. When low-income individuals cannot afford substantial time savings, they are compelled to spend more time on home labor; therefore, implementing a tax rule that penalizes home labor implies that they face higher tax rates than high-income individuals. 
Besides the obvious equity concerns, the problem with such a rule is that higher taxes may force low-income individuals to increase home labor even more. This can lead to greater marginal welfare costs of taxation or even to a reduction of tax collections, which by itself justifies a lower tax burden. The second qualification addresses this problem: Optimal commodity tax rates do not depend only on the amount of time savings (or home labor) associated with market goods, but also on the marginal effect of the tax rate on those time savings. A higher tax rate can induce a taxpayer to replace a market good with another, more affordable, market good that saves less time. As a result, the full price of the basic commodity, equal to the price of the market good plus the opportunity cost of home labor, increases at a rate greater than the tax rate. Optimal tax rates should be lower when their marginal effect on time savings is greater. Goods that offer greater time savings compared to their more affordable substitutes, should be taxed at lower rates.

Examples of time-saving goods that may be assigned low tax rates at the optimal solution proposed in this paper, but have been associated with higher optimal tax rates in the related literature, are those used for transportation. As long as some market goods allow low-income individuals to obtain significant time savings with respect to alternative means of transportation (e.g. cars with respect to buses; or buses with respect to bicycles), they should be favored with lower tax rates and it may even be optimal for the government to subsidize them. The tax system should not penalize low-income individuals for using time-consuming means of transportation, but instead it may have to help making time-saving means of transportation more affordable.

The framework developed in this paper, in which market goods can replace each other in the production of basic commodities, is generally incompatible with the assumptions of 
hometheticity among market goods and weak separability of market goods and leisure. ${ }^{1}$ This means that the classic uniformity results due to Sandmo (1974) and Atkinson and Stiglitz (1976) do not hold in this framework. The presence of time-saving goods ensures that there is a role for differential commodity taxation and the time-saving rule derived in this paper even when income taxes are set optimally.

The paper is organized as follows. Section 2 analyzes the effect of income changes on home production in the presence of time-saving goods. Section 3 solves the time allocation problem with one basic commodity and introduces the concept of time inequality. Section 4 considers many basic commodities and analyzes the effect of time savings on basic optimal tax rules. Section 5 concludes.

\section{Home production with time-saving goods}

Leisure $\rho$ is defined here as enjoyable time, regardless of whether it is associated with market goods or not. ${ }^{2}$ It makes a positive contribution to utility, but it is costly to the individual. Market labor $\lambda$ is not enjoyable, but it contributes to individual welfare with income. A third concept of time, based on Becker's (1965) seminal paper, is home or non-market labor $\sigma$, which generates no income and is assumed to be not enjoyable, even though it is spent in producing (either at home or not) goods that could otherwise be bought in the market. The individual time constraint is

\footnotetext{
${ }^{1}$ Homothetic preferences for market goods imply that spending on each market good increases proportionally with the level of income, but this cannot happen if some goods are replaced by others. Since goods that provide more time savings are replacing those providing less time savings as income increases, we know that there are inferior and normal goods and thus preferences cannot be homothetic. In addition, the time-saving attribute of a good implies that its consumption can have a direct effect on leisure and thus preferences cannot, in general, be weakly separable between goods and leisure.

2 This definition corresponds to the concept of "full leisure" used by Boadway and Gahvari (2006), equal to the sum of pure leisure and the time used consuming perfect leisure-substitutes.
} 


$$
\kappa=\rho+\sigma+\lambda
$$

where $\kappa$ is total time available.

In the home production literature a given home labor requirement $\sigma^{r}$ must be combined with a market good $x_{0}$ to produce a basic commodity $z=Z\left(\sigma^{r}, x_{0}\right)$, where $Z(\cdot)$ is a production function. This section analyzes a case that has not yet received attention in the literature: The production of $z$ when home labor $\sigma$ can be reduced with time-saving goods, such that $\sigma$ does not need to be equal to $\sigma^{r}$ and, more generally, $0 \leq \sigma \leq \sigma^{r}$. In order to formally define time-saving goods, the variable $\sigma^{r}$ is divided into $M$ mutually exclusive activities or improvements, each representing a share or fraction of time $\sigma_{s m}$ (where $m=1, \ldots, M$ and $\sum_{m=1}^{M} \sigma_{s m}=1$ ) of the time $\sigma^{r}$ required to produced each unit of $z$, and valued at a price $\pi_{m}$ in the market.

A time-saving good is defined as a market good that reduces the amount of home labor $\sigma$ used in the production of each unit of $z$, either because it does not require the consumer to perform one or more activities for the production of $z$, or alternatively because it offers improvements that reduce the home labor requirement or make consumption time enjoyable, allowing the user to transform home labor time into leisure time. Time-saving goods can be used to describe very common consumption choices in which certain activities are directly hired at a market price (e.g. assistants, maids, gardeners, etc.) or paid for as part of the price of goods with some value added. ${ }^{3}$ In general, time-saving goods allow the individual to increase market labor, leisure, or both.

\footnotetext{
${ }^{3}$ Prepared meals (e.g. frozen pizza) are examples of goods that save the time spent in the activity "cooking." In some cases market goods offer qualitative improvements that save time. A cleaner, for instance, is said to be of better quality if, other things equal, it requires less time to remove a stain. Luxury cars are examples of market goods that offer enjoyable improvements, which may allow to transform the home labor time used in transportation into leisure time.
} 
For concreteness, if $z$ corresponds to the basic commodity "dinner," $x_{0}$ can be defined as the market good "food," which can be bought in the market at a price $p$. In order to produce one $z$ the individual requires one unit of $x_{0}$ and a fixed amount of home labor time $\sigma^{r}$, which can be divided into several activities or improvements. For example, a share $\sigma_{s 1}$ is devoted to purchasing the food, another share $\sigma_{s 2}$ is devoted to cooking, another share $\sigma_{s 3}$ is spent washing the dishes, and another share $\sigma_{s 4}$ is spent eating. In this example, $\sum_{m=1}^{4} \sigma_{s m}=1$. A possible choice is to buy only food $x_{0}$ at the market price $p$, in which case there are no time savings and home labor $\sigma$ remains equal to $\sigma^{r}{ }^{4}$ To-go food is a different market good, denoted here as $x_{1}$, that saves the time required to cook, such that $\sigma=\sigma^{r}-\sigma_{s 2}$, and has a market price $p+\pi_{2} \sigma_{s 2}$. Delivery food, $x_{2}$, would save the time spent on purchasing the food and cooking, so its price is even higher and equal to $p+\sum_{m=1}^{2} \pi_{m} \sigma_{s m}$. An equivalent option is to pay one or more persons to perform these tasks. Alternatively, a visit to a restaurant, $x_{3}$, would save the time spent cooking and washing the dishes (assuming that the time spent going there equals the time that would have been spent purchasing food), and may add other valuable attribute like social interaction, which may allow to transform the time share $\sigma_{s 4}$ of home labor into leisure time. The resultant market price of a dinner in the restaurant is $p+\sum_{m=2}^{4} \pi_{m} \sigma_{s m} \cdot{ }^{5}$

The remaining of this section shows how the use of time-saving goods affects the optimal production decision about $z$, which is for simplicity assumed to be the only basic commodity produced by the individual. Following a common practice in the related literature, the production

\footnotetext{
${ }^{4}$ Strictly speaking, given that all market goods require some labor to be produced, they can all be considered to save time. Even the market good "food," for instance, saves the individual the time required to collect or produce food on her own.

${ }^{5}$ As explained, even the time used on driving to the restaurant could be "saved" if this activity is made enjoyable, for instance, with a luxury car. This improvement, of course, affects only the price of the car, not the price of the dinner at the restaurant. For the purpose of the analysis, however, a market good might be assumed to be a good that integrates all time savings accumulated in the overall experience of going to the restaurant.
} 
function is assumed to have a Leontief form where each unit of $z$ is produced with one unit of the home labor requirement $\sigma^{r}$ and one unit of market good, thus both inputs are perfect complements. ${ }^{6}$ Different from previous papers, however, it is assumed that the home labor can be reduced by purchasing time-saving goods $x_{i}, i=1, \ldots, n, \ldots, N$, each with different amounts of valuable time savings at different prices.

For convenience, the available time-saving shares $\sigma_{s m}$ are assumed to be ordered from the cheapest to the most expensive one, such that their prices satisfy $\pi_{1} \leq \cdots \leq \pi_{M}$. Similarly, time-saving goods $x_{i}$ are ordered in terms of the total time-saving share that they offer (with $x_{0}$ offering no time savings). Disregarding the possibility that different market goods may in practice offer the same total time-saving share, each $x_{i}$ is assumed to add the next cheapest timesaving share to the total provided by the previous market good $x_{i-1}$. Taken together, these two assumptions imply that $M=N$; that any given $x_{n}$ adds a time-saving share $\sigma_{s n}$ with price $\pi_{n}$ (note the change in subscripts); and that $x_{n}$ has a market price $p+\sum_{i=1}^{n} \pi_{i} \sigma_{s i}$ and is the least expensive good that provides a total time-saving share not lower than $\sum_{i=1}^{n} \sigma_{s i}$. Furthermore, considering that by assumption one unit of $z$ always requires one unit of the market good and one unit of the time requirement, then total time savings provided by $x_{n}$ are $x_{n} \sum_{i=1}^{n} \sigma_{s i}$, and the market cost of these time savings is $x_{n} \sum_{i=1}^{n} \pi_{i} \sigma_{s i}$.

The problem of maximizing the amount of $z$ is twofold, as it requires not only to obtain the optimal amount of the market good that is used to produce $z$, but also to determine what precise market good(s) should be chosen. Focusing for now on the first of these two problems,

\footnotetext{
${ }^{6}$ See Kleven (2004) and Boadway and Gahvari (2006) for examples of how home production is modeled in the optimal taxation literature. An alternative approach can be found in Gronau (1977), who uses a more general production function and assumes perfect substitutability between goods produced at home and goods purchased in the market.
} 
and denoting total time-saving under $x_{n}$ as $\sigma_{s}=\sum_{i=1}^{n} \sigma_{s i}$ to simplify notation, the Leontief production function is defined, for any given $x_{n}$, as

$$
z\left(\sigma, \sigma_{s}, x_{n}\right)=\min \left\{\sigma+x_{n} \sigma_{s}, x_{n}\right\}
$$

The marginal rate of technical substitution and the optimal production condition are

$$
\begin{aligned}
& \text { MRTS }=-\frac{\frac{\partial z\left(\sigma, \sigma_{s}, x_{n}\right)}{\partial \sigma}}{\frac{\partial z\left(\sigma, \sigma_{s}, x_{n}\right)}{\partial x_{n}}}=\left\{\begin{array}{cc}
-\frac{1}{\sigma_{s}} & \text { if } \sigma+x_{n} \sigma_{s} \leq x_{n} \\
0 & \text { if } \sigma+x_{n} \sigma_{s}>x_{n}
\end{array}\right. \\
& \sigma=\left(1-\sigma_{s}\right) x_{n} .
\end{aligned}
$$

Production possibilities are limited by the following time and budget constraints:

$$
\begin{aligned}
& \bar{\kappa}=\sigma+\lambda, \\
& w \lambda=\left(p+\sum_{i=1}^{n} \pi_{i} \sigma_{s i}\right) x_{n},
\end{aligned}
$$

where $w$ is the wage rate. The time constraint (4.a) implicitly defines total leisure time $\rho=\kappa-$ $\bar{\kappa}$ as fixed. ${ }^{7}$ The optimal value of (full) leisure is determined by the utility maximization decision, which is addressed in the next section.

Using (3.b), (4.a) and (4.b) we can obtain the optimal amounts of $x_{n}$ and $\sigma$ :

$$
\begin{aligned}
& x_{n}^{*}=\frac{w \bar{\kappa}}{P}, \\
& \sigma^{*}=\frac{w \bar{\kappa}}{P}\left(1-\sigma_{s}\right),
\end{aligned}
$$

where $P$ represents the "full price" of $z$ under $x_{n}$, defined as

$$
P=p+\sum_{i=1}^{n} \pi_{i} \sigma_{s i}+w\left(1-\sigma_{s}\right)
$$

\footnotetext{
${ }^{7}$ Note that the time saved by improvements that make consumption time enjoyable, which provides no additional time available for production, is implicitly assumed to be exchanged with equal amounts of time spend on "pure leisure," such that "full leisure" $\rho$ (as defined by Boadway and Gahvari 2006), remains unchanged.
} 
$P$ is equal to the market price of $x_{n}$ plus the monetary value of time spent on producing one unit of basic commodity (instead of working in the market). ${ }^{8}$ A key implication of (5.c) is that as long as $w>\pi_{i}, P$ decreases with $\sigma_{s i}$. Whenever the price of an activity $i$ is lower than the wage rate, additional time savings reduce the full price of the basic commodity and the time required for that activity is better spent supplying labor in the market rather than in home labor. ${ }^{9}$ For this reason, if $w>\pi_{i}$, a utility maximizing taxpayer will always choose to purchase the good that saves the time spent in activity $i$ in the market. This result is now used to explain the choice of the specific market good $x_{n}$ that maximizes the production of $z$.

Figure 1 illustrates the effect of using different time-saving goods on the production of $z$. The horizontal axis represents total time available for labor, either at home or in the market, and the vertical axis represents whatever market good $x_{i}$ is being used to produce $z .{ }^{10}$ In the absence of time savings the optimality condition (3.b) is reduced to $\sigma=x_{0}$. The corresponding equilibrium is found at $e_{0}$, where the line representing this condition intercepts the budget constraint $c_{0} \bar{\kappa}$. The maximum attainable level of production is $z_{1}$, which is the level of the dashed isoquant with the typical ninety degree L-shape.

\footnotetext{
${ }^{8}$ From this definition of the full price of $z$ it is possible to derive alternative expressions provided in the literature, where it is commonly assumed that a market good $x$ and $\sigma$ are used in fixed proportions, but where there is no account for possible benefits and costs of time savings. For instance, Boadway and Gahvari (2006) define $a$ as the fixed amount of time required to consume one unit of $x$. Although they do not explicitly address the production problem, we can rewrite (2) to represent the framework implicitly used by them as $z^{\prime}\left(a, x_{n}\right)=\min \left\{a x_{n}, x_{n}\right\}$. This function leads to the optimal production condition $a x_{n}=x_{n}$, which implies $a=1$. It is easy to see that the full price of $x$ computed by Boadway and Gahvari (2006), $p+w a$, is equivalent to the full price of $\mathrm{z}$ in the absence of time savings $\left(\sigma_{s}=0\right)$.

${ }^{9}$ Related papers on optimal commodity taxation in the presence of home labor do not reach this conclusion because are based on the assumption that each basic commodity $z$ can be produced with only one market good that is combined with a fixed amount of home labor. Since substitution among market goods to produce the same $z$ is disregarded, utility is maximized by allowing for substitution only among different basic commodities. The problem with the last approach is that it obscures the fact that a higher a wage rate $w$ allows to purchase more time savings and thus produce the same basic commodity with less home labor, increasing the ability of the individual to produce $z$ and also to enjoy more leisure time.

${ }^{10}$ Recall that by definition one unit of any market good $x_{i}$ is used to produce one unit of $z$, thus the amount of any market good used is necessarily equal to the production of basic commodity $x_{i}=z$.
} 
When a time-saving good $x_{1}$ with time-saving share $\sigma_{s 1}$ is introduced, the new optimality condition becomes $\sigma=\left(1-\sigma_{s 1}\right) x_{1}$. ${ }^{11}$ Any time-saving good would allow the individual to reduce home labor, but the extent to which it will allow them to increase the production of $z$ depends on the relation between the price of the time saved, $\pi_{1}$, and the wage rate $w$. If $\pi_{1}=w$, the marginal cost of reducing home labor is equal to the marginal gain from increasing market labor. In this case the budget constraint is $c_{1} \bar{\kappa}$, and one unit of market labor buys exactly one unit of home labor. The equilibrium is at $e_{1}$, where the level of production remains unchanged at $z_{1}$.

For illustration purposes, let the price of $\sigma_{s 1}$ be reduced to $\pi_{1}^{\prime}<w$. In this case one unit of market labor buys more than one unit of home labor, so it is optimal to use the time required by that activity in the labor market. The budget constraint moves to $c_{2} \bar{\kappa}$ and production increases up to $z_{2}=x_{1}^{*}$, where the asterisk denotes that the value of $x_{1}$ under $\pi_{1}^{\prime}$ is optimal. The new equilibrium is found at $e_{2}$, where home labor is $\sigma^{*}=\left(1-\sigma_{s 1}\right) x_{1}^{*}$, market labor is $\bar{\kappa}-\sigma^{*}$, and $\sigma_{s 1} x_{1}^{*}=\sigma_{s 1} z_{2}$ is the amount of time purchased in the market. Production increases under $\pi_{1}^{\prime}$ because the individual has been able to increase the amount of "effective" time used from $\bar{\kappa}$, as defined by (4.b), to $\bar{\kappa}+\sigma_{s 1} x_{1}^{*}$. Whenever the cost of an additional time-saving share is lower than the wage rate, production maximization leads to a net gain of effective time.

\footnotetext{
${ }^{11}$ The new isoquant is no longer vertical when $\sigma+\sigma_{s 1} x_{1} \leq x_{1}$; it has a slope equal to $-1 / \sigma_{s}$ according to (3.a), and meets the vertical axis at $h_{1}$. This is because the purchase of $x_{1}$ is equivalent to an increase of $x_{0}$ accompanied with additional time that further increases $z$.
} 


\section{Figure 1. Time-saving goods and production of a basic commodity}

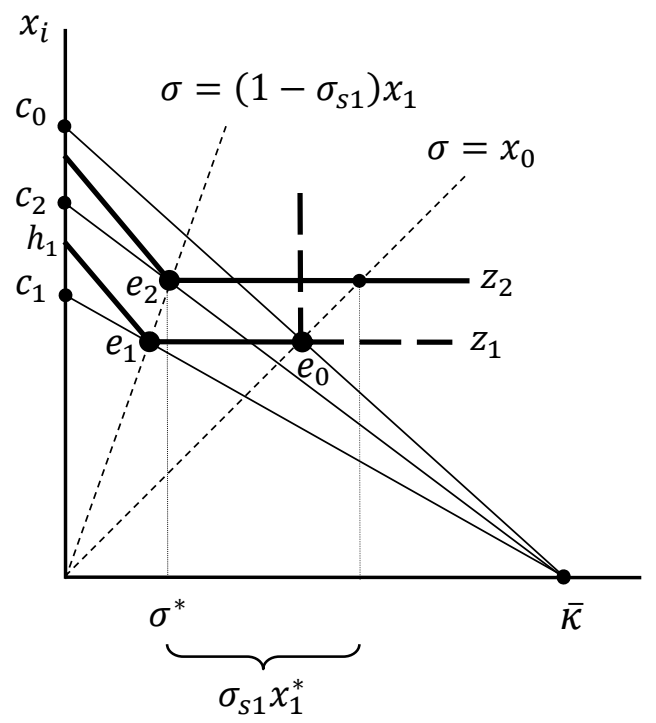

It is apparent that the level of the wage rate $w$ determines the specific time-saving good $x_{n}$ that maximizes the level of production, and thus also the amount of time savings that the product maximizing individual will obtain. ${ }^{12}$ In general, as long as time-saving shares of increasing market prices are individually added by subsequent time-saving goods, the specific time-saving good $x_{n}$ that leads to the optimal level of production $z^{*}$ will be the one that adds the most expensive time-saving share $\sigma_{s n}$ that satisfies $\pi_{n} \leq w$.

It is also apparent that the higher the wage rate the greater the total time-saving share will be. Assuming for convenience the presence of infinitely many $x_{i}$ available in the market for the production of $z$, then $\sigma_{s}=\sigma_{s}\left(w, p, \pi_{1}, \ldots, \pi_{n}\right)$ can be defined as a differentiable function that describes the total time-saving share associated with the solution to the production problem, and write this conclusion as

\footnotetext{
${ }^{12}$ An increase in non-labor income makes additional time savings affordable and consequently may imply that it is optimal to use goods for which $\pi_{i}>w$. For the sake of clarity, this case is disregarded and income is assumed to be obtained only from labor.
} 


$$
\frac{\partial \sigma_{s}}{\partial w} \geq 0
$$

which is defined for $\sigma_{s} \in[0,1]$ and holds with equality when $\sigma_{s}=1$. The individual will purchase additional time savings (in the form of a more expensive time-saving good) up to the point where $\pi_{n}=w$, which describes the value of $\sigma_{s}$ that maximizes production for a given budget constraint and level of leisure. Furthermore, if $w$ is high enough, it is plausible to fully eliminate home labor, such that $\sigma_{s}=1$.

\section{Utility maximization with time-saving goods}

This section analyzes the solution to the utility maximization problem with time-saving goods and one basic commodity $z$. Leisure is treated as an endogenous variable and the time available for production, assumed fixed in the previous section, is thus allowed to vary as well.

Considering the form of the production function in (2) and assuming $\pi_{n}=w$, we know that at the solution to the production problem $x_{n}=z$. Maintaining the assumptions that there are infinitely many market goods $x_{i}$ and that $\sigma=\sigma(\cdot)$ is a differentiable function (described at the end of the last section), the optimal production condition (3.b) and the budget constraint (4.b) can be rewritten as

$$
\begin{aligned}
& \sigma=\left(1-\sigma_{s}\right) z, \\
& w \lambda=\left(p+\pi \sigma_{s}\right) z,
\end{aligned}
$$

where the market price of $\sigma_{s}$ is represented by $\pi<\pi_{n}=w$, which is from now on assumed to be constant. ${ }^{13}$

\footnotetext{
${ }^{13}$ This assumption is made for simplicity, even though (the higher prices of) additional time-saving shares necessarily increase $\pi$. Since prices $\pi_{i}$ and the total time-saving share $\sigma_{s}(\cdot)$ vary simultaneously and in the same direction, this assumption does not significantly affect the results of the model.
} 
The individual maximizes a quasi-concave, twice-differentiable utility function $u(z, \rho)$ whose value increases with the consumption $z$ and leisure time $\rho$. Using this function as well as the constraints (1), (7.a) and (7.b), the Lagrangian expression of the problem is

$$
L=u(z, \rho)+\alpha\left(w \kappa-w \rho-\left[p+\pi \sigma_{s}+w\left(1-\sigma_{s}\right)\right] z\right),
$$

where $\alpha$ is the multiplier, equal to the marginal utility of income. The first order conditions for the optimal choices of $z$ and $\rho$ lead to the following optimal condition:

$$
\frac{\frac{\partial u}{\partial \rho}}{\frac{\partial u}{\partial z}}=\frac{w}{p+\pi \sigma_{s}+w\left(1-\sigma_{s}\right)}
$$

The right hand side of (8) represents the opportunity cost of leisure, while its denominator corresponds to $P$, the full price of $z$. Provided $w>\pi$, an increase in $\sigma_{s}$ reduces $P$ and increases the opportunity cost of leisure. Since the individual is assumed to be able to freely substitute among infinitely many market goods with different time-saving shares and market prices, then the marginal effect of $w$ on $P$ is

$$
\frac{\partial P}{\partial w}=1-\sigma_{s}-(w-\pi) \frac{\partial \sigma_{s}}{\partial w}
$$

Provided (6) and $w>\pi$, the effect of $w$ on $P$ can be positive or negative, but it will necessarily decrease with the time-saving share $\sigma_{s}$ and marginal time savings $\partial \sigma_{s} / \partial w{ }^{14}$

Figure 2 describes the optimal time allocation decision in the presence of time-saving goods. The vertical axis represents the basic commodity $z$ and the horizontal axis represents time, with the sum of home labor and leisure increasing rightward, and market labor increasing from the time constraint $\kappa$ to the left. The budget constraint $d_{1} \kappa$ corresponds to a situation in

\footnotetext{
${ }^{14}$ Boadway and Gahvari (2006) also allow for the full price of $z$ to change with $w$, but do not account for the effect of $w$ on time savings or, equivalently, on the home labor requirement of market goods.
} 
which individual's home labor $\sigma$ is fully replaced with time savings $\left(\sigma_{s}=1\right)$. As in the most traditional time allocation framework where by assumption $\sigma=0$, any equilibrium point on this budget constraint separates total time available into leisure and market labor. For example, the equilibrium at $e_{1}$ (indifference curves not shown) is associated with a level of consumption $z^{*}$, leisure time $\rho_{1}^{*}$ and market labor $\lambda_{1}^{*}$.

In contrast, if income is not high enough to fully replace home labor $\left(\sigma_{s}<1\right)$ then $P$ would be higher and the opportunity cost of leisure lower. This situation is represented by the budget constraint $d_{2} \kappa$. More time must be spent in home labor per unit of $z$ consumed, leaving less time available for leisure. The new equilibrium at $e_{2}$ is, for clarity, assumed to be associated with the same consumption level $z^{*}$ and market labor $\lambda_{1}^{*}$, but leisure has been reduced to $\rho_{2}^{*}$ and home labor, equal to the horizontal distance between the two budget constraints at $z^{*}$, has increased up to $\sigma_{2}^{*}=\left(1-\sigma_{s}\right) z^{*}$.

Subsequent reductions of $\sigma_{s}$ continue to increase the full price of $z$ until it reaches its maximum when $\sigma_{s}=0$, where $P=p+w$. Importantly, nothing ensures that leisure is greater than zero in that case. The equilibrium at $e_{3}$ shows a situation in which the time available is depleted by market and home labor, and no time is left for leisure.

Two polar cases can be recognized in Figure 2. For any given level of non-labor income, there may be a minimum wage rate $w^{h}$ for which (and above which) home labor is zero, as in point $e_{1}$. Similarly, there may be a maximum wage rate $w^{l}$ for which (and below which) leisure is zero, as in point $e_{3}$. In the presence of home labor requirements, case $w^{h}$ implies $\sigma_{s}=1$ and case $w^{l}$ implies $\sigma_{s}=0$. Home labor and leisure are both greater than zero if and only if the individual's wage rate is $w$ and $w^{l}<w<w^{h}$. 
Figure 2. Utility maximization with time-saving goods

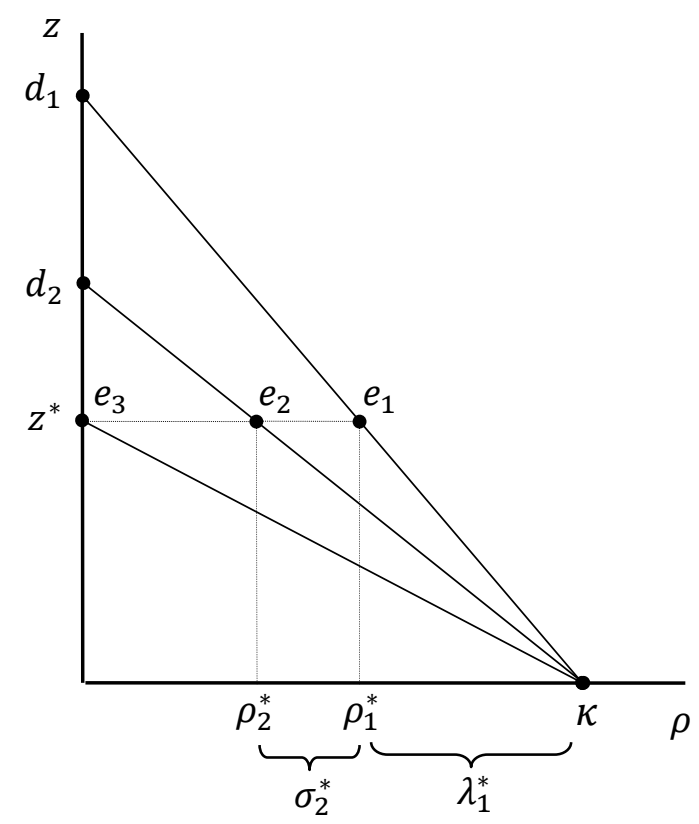

The different patterns of time allocation for high and low income individuals imply that the traditional concept of income inequalities is associated with a similar concept of time inequalities, whereby low-income individuals are less able to enjoy leisure time than highincome individuals. ${ }^{15}$ This conclusion is relevant for the optimal tax literature, routinely concerned with finding efficient mechanisms to indirectly tax leisure. The next section analyzes some of the consequences of considering time savings and time inequalities in the theory of optimal commodity taxation.

\footnotetext{
15 The related concept of time poverty was introduced by Vickery (1977) to describe those cases where the time available for home production is below a predefined poverty threshold. This definition does not imply, however, that time poverty is related to income poverty. Recent discussions about time poverty can be found in Zacharias (2011), Antonopoulos, Masterson and Zacharias (2012), and Merz and Rathjen (2014).
} 


\section{Time savings and optimal commodity taxation}

The time inequalities created by differences in access to time-saving goods have important implications for optimal taxation. One is that commodity tax rates for high-income individuals that are able to eliminate home labor should be assigned in accordance to the original Corlett and Hague (1953-54) rule: Optimal tax rates are higher for those goods that are more complementary to leisure. This conclusion is equivalent to the one reached by Boadway and Gahvari (2006) for the case in which all the time spent in consumption is a perfect leisuresubstitute. Under that assumption the time spent in consumption is always enjoyable, a situation that can be reproduced with time-saving goods when $\sigma_{s}=1$. The case of labor-substitutes considered by Boadway and Gahvari (2006) is captured by a situation in which it is not optimal to fully eliminate home labor $\left(\sigma_{s}<1\right)$. It is under this condition that the presence of time savings leads to adjustments to the original Corlett and Hague rule, as well as to the correction of optimal tax rules derived by recent contributions incorporating home production into the optimal tax problem.

In order to analyze the effects of time-saving goods on the traditional Corlett and Hague rule, the model introduced in Section 3 is modified to include many basic commodities $z_{j}, j=$ $1, \ldots, J$, each produced with one non-time-saving good with normalized price $p$ and a time-saving component $\sigma_{s j}$ with a given market price $\pi_{j}$. Taken together, these two components can be considered as one market good $x_{j}$ with producer price $p+\pi_{j} \sigma_{s j}$. Considering a per unit tax $t_{j}$ the full price of $z_{j}$ is $P_{j}=p+\pi_{j} \sigma_{s j}+t_{j}+w\left(1-\sigma_{s j}\right)$. Given that $t_{j}$ reduces the purchasing power of the individual, it is assumed to have a negative effect on $\sigma_{s j}$. Provided $w \geq \pi_{j}$, the effect of $t_{j}$ on $P_{j}$ is 


$$
\frac{\partial P_{j}}{\partial t_{j}}=1-\left(w-\pi_{j}\right) \frac{\partial \sigma_{s j}}{\partial t_{j}} \geq 1
$$

The greater the reduction of $\sigma_{s j}$ due to the tax, the greater the marginal (positive) effect of $t_{j}$ on the full price $P_{j}$.

Using $\bar{Z}$ to denote the vector of all basic commodities, the corresponding Lagrangian and first order conditions are

$$
\begin{aligned}
& L^{\prime}=u(\bar{z}, \rho)+\alpha\left(w \kappa-w \rho-\sum_{j=1}^{J} P_{j} z_{j}\right) \\
& \left(z_{k}\right) \quad \frac{\partial u}{\partial z_{k}}-\alpha P_{j}=0, k=1, \ldots, J \\
& \text { ( }) \quad \frac{\partial u}{\partial \rho}-\alpha w=0 .
\end{aligned}
$$

The solution to this problem leads to demand functions $z_{j}(\bar{P}, w), \rho(\bar{P}, w)$, and the indirect utility $v(\bar{P}, w)$, where $\bar{P}$ is the vector of full prices. Since by assumption one unit of a basic commodity is produced with one unit of a market good, then $x_{j}(\bar{P}, w)=z_{j}(\bar{P}, w)$, and $P_{j}$ can be interpreted as the full price of $x_{j}$. The Lagrangian expression for this problem can therefore be rewritten as

$$
L^{\prime \prime}=v(\bar{P}, w)-\alpha\left(w \kappa-w \rho-\sum_{j=1}^{J} P_{j} x_{j}\right)
$$

By the envelope theorem

$$
\frac{\partial v}{\partial P_{k}} \frac{\partial P_{k}}{\partial t_{k}}=-\alpha \frac{\partial P_{k}}{\partial t_{k}} x_{k}
$$

where $\partial P_{k} / \partial t_{k}=1-\left(w-\pi_{k}\right) \partial \sigma_{s k} / \partial t_{k} \geq 1$.

The problem for the government is to choose the commodity tax rates $t_{j}, j=1, \ldots, J$, that maximize individual utility given an exogenously determined revenue requirement $R$. The 
corresponding Lagrangian expression and the first order condition for the optimal choice of $t_{k}$ are

$$
\begin{gathered}
L^{\prime \prime \prime}=v(\bar{P}, w)+\mu\left\{-R+\sum_{j=1}^{J} t_{j} x_{j}(\bar{P}, w)\right\} \\
\frac{\partial v}{\partial P_{k}} \frac{\partial P_{k}}{\partial t_{k}}+\mu\left[x_{k}+\sum_{j=1}^{J} t_{j} \frac{\partial x_{j}}{\partial P_{k}} \frac{\partial P_{k}}{\partial t_{k}}\right]=0
\end{gathered}
$$

where $\mu$ is the multiplier, equal to the marginal welfare cost of tax collections. Using (9) and the Slutzky equation, the first order condition is equal to

$$
-\alpha \frac{\partial P_{k}}{\partial t_{k}} x_{k}+\mu x_{k}+\mu \frac{\partial P_{k}}{\partial t_{k}} \sum_{j=1}^{J} t_{j}\left(\frac{\partial x_{j}^{c}}{\partial P_{k}}-x_{k} \frac{\partial x_{j}}{\partial m}\right)=0
$$

where $x_{j}^{c}$ is the compensated demand for $x_{j}$ and $m$ is non-labor income. Dividing by $\mu x_{k} \partial P_{k} / \partial t_{k}$ and using symmetry of substitution we obtain

$$
\frac{1}{\frac{\partial P_{k}}{\partial t_{k}}}+\frac{1}{x_{k}} \sum_{j=1}^{J} t_{j} \frac{\partial x_{k}^{c}}{\partial P_{j}}=\frac{\alpha}{\mu}+\sum_{j=1}^{J} t_{j} \frac{\partial x_{j}}{\partial m} .
$$

Given that the right hand side of this equation is identical for all $k=1, \ldots, J$, and considering for simplicity only $k=1,2$, we can write

$$
\frac{1}{\frac{\partial P_{1}}{\partial t_{1}}}+t_{1}\left[\frac{1}{x_{1}} \frac{\partial x_{1}^{c}}{\partial P_{1}}-\frac{1}{x_{2}} \frac{\partial x_{2}^{c}}{\partial P_{1}}\right]=\frac{1}{\frac{\partial P_{2}}{\partial t_{2}}}+t_{2}\left[\frac{1}{x_{2}} \frac{\partial x_{2}^{c}}{\partial P_{2}}-\frac{1}{x_{1}} \frac{\partial x_{1}^{c}}{\partial P_{2}}\right]
$$

Multiplying the parenthesis in the left hand side by $P_{1} / P_{1}$ and the parenthesis in the right hand side by $P_{2} / P_{2}$,

$$
\frac{1}{\frac{\partial P_{1}}{\partial t_{1}}}+\frac{t_{1}}{P_{1}}\left[\varepsilon_{x_{1}, P_{1}}^{c}-\varepsilon_{x_{2}, P_{1}}^{c}\right]=\frac{1}{\frac{\partial P_{2}}{\partial t_{2}}}+\frac{t_{2}}{P_{2}}\left[\varepsilon_{x_{2}, P_{2}}^{c}-\varepsilon_{x_{1}, P_{2}}^{c}\right]
$$

where $\varepsilon_{x_{k}, P_{j}}^{c}$ is the compensated price elasticity of $x_{k}$ with respect to $P_{j}$. Provided that the demand functions $x_{k}(\bar{P}, w)$ are homogeneous of degree 0 , the Euler's theorem implies that 
$\varepsilon_{x_{k}, P_{1}}^{c}+\varepsilon_{x_{k}, P_{2}}^{c}+\varepsilon_{x_{k}, w}^{c}=0$, where $w$ stands as the price of leisure. Using this equality, (10) can be rewritten as

$$
\frac{t_{1}}{P_{1}}\left[\varepsilon_{x_{1}, P_{1}}^{c}+\varepsilon_{x_{2}, P_{2}}^{c}+\varepsilon_{x_{2}, w}^{c}\right]-\frac{t_{2}}{P_{2}}\left[\varepsilon_{x_{1}, P_{1}}^{c}+\varepsilon_{x_{2}, P_{2}}^{c}+\varepsilon_{x_{1}, w}^{c}\right]=\frac{\frac{\partial P_{1}}{\partial t_{1}}-\frac{\partial P_{2}}{\partial t_{2}}}{\frac{\partial P_{1}}{\partial t_{1}} \frac{\partial P_{2}}{\partial t_{2}}} .
$$

The classic Corlett and Hague rule can easily be obtained from this result. For the high-income case where time savings are no longer possible, $\partial \sigma_{s k} / \partial t_{k}=0$ and $\partial P_{k} / \partial t_{k}=1$, such that the right hand side of (11) is zero. Provided $\varepsilon_{x_{1}, P_{1}}^{c}+\varepsilon_{x_{2}, P_{2}}^{c}<0$, the highest proportional tax rate $t_{k} / P_{k}$ should be imposed on that good that is more complementary with leisure, which is the good with the lowest $\varepsilon_{x_{k}, w}^{c}$. Without loss of generality, we can assume that good 1 is more complementary with leisure $\left(\varepsilon_{x_{1}, w}^{c}<\varepsilon_{x_{2}, w}^{c}\right)$. In accordance to the Corlett and Hague rule, in this case $t_{1} / P_{1}>t_{2} / P_{2}$. The good that is more complementary to leisure should face a tax that represents a greater proportion of the full price of the good.

Whenever $\sigma_{s k}<1$, the full price of $x_{k}$ is higher than its market price $p+\pi_{k} \sigma_{s k}+t_{k}$, and this difference decreases with the value of $\sigma_{s k}$. This is important because it implies that the optimal tax $t_{k}^{*}$ computed under (11) represents a smaller tax rate with respect to the market price as the opportunity cost of home labor, $w\left(1-\sigma_{s k}\right)$, increases as a proportion of $P_{k}$. Provided that $p$ is the same for all goods, and given that time savings and their prices are expected to change in the same direction, then the tax rate decreases with more time savings. Goods that save more time per dollar in average should be taxed at lower rates than in the Corlett and Hague rule. This result is similar to previous findings by Kleven, Richter, and Sorensen (2000) and Kleven (2004), who call for lower tax rates on market services that reduce home labor, ${ }^{16}$ and by Gahvari

\footnotetext{
${ }^{16}$ Kleven (2004) explicitly mentions market goods that "save time"; however, he does not introduce costly time savings in his model.
} 
and Yang (1993), who suggest to apply higher tax rates on goods with greater time requirements. In these cases, it does not matter whether the home labor time is enjoyable or not. The result obtained is, however, equivalent to the Boadway and Gahvari's (2006) conclusion about applying higher tax rates to goods that require more (unpleasant) home labor.

The explicit account of costly time savings adds new insights to the problem of the optimal taxation of time. As long as time savings are used to increase (pure) leisure time, or correspond to improvements that make consumption enjoyable, then leisure is being purchased in the market at price $\pi_{k}$. Contrary to the common presumption in the literature, leisure is (at least partially) taxable, and it should receive favorable tax treatment under an optimal commodity tax system for two reasons. One is that leisure is available in the market through time savings that should be subject to lower tax rates; the other is that leisure is taxed at its market price $\pi_{k}$, which is lower than $w$. In contrast, home labor is subject to higher optimal commodity tax rates applied on its opportunity cost $w$. This means that tax policy prescriptions available in the literature may have unintended regressive effects: Since lower-income individuals are less able to purchase time savings, then they would be faced with higher tax rates.

Based on (11), a new tax rule not yet identified in the literature can be formulated. If $\sigma_{s k}<1$ for at least one market good $k$, the right hand side of (11) will likely be different than zero. It would be negative if $t_{1}$ has a smaller effect on the corresponding full price than $t_{2}\left(t_{1}\right.$ has a smaller impact on time savings per dollar than $\left.t_{2}\right)$, and in that case $t_{1} / P_{1}$ should be higher than suggested by the Corlett and Hague rule. Alternatively, the right hand side of (11) is positive when $t_{1}$ has a greater effect on time savings per dollar than $t_{2}$, and in that case $t_{1} / P_{1}$ should be lower than suggested by the Corlett and Hague rule. In the latter case, contrary to the Corlett and Hague rule, the good that is more complementary with leisure could be associated with the 
lowest optimal tax rate. ${ }^{17}$ The intuition is simple. Goods that offer relatively more time savings per dollar in the margin should also be taxed at a lower rate that other goods in order to make more time available for market labor and leisure. This rule allows to partially correct for the regressive effects of taxes in the presence of costly time-saving goods, by minimizing the impact of tax rates on the home labor requirements of lower-income individuals.

The results obtained in (11) can be summarized by a new "time-saving rule," which calls for lower tax rates on goods that provide greater time savings, both in average and in the margin, and that becomes more relevant as the goods are purchased by lower-income individuals. As long as $0<\sigma_{s k}<1$ the time-saving rule must be considered together with the traditional Corlett and Hague rule to obtain the optimal tax rates. Two special cases are obtained when either leisure is zero or home labor is zero. When a low-income individual can no longer buy any leisure $\left(\sigma_{s k}=0\right)$, complementarity with leisure becomes irrelevant and thus $\varepsilon_{x_{1}, w}^{c}=\varepsilon_{x_{2}, w}^{c}=0$, implying that only the time-saving rule applies. In contrast, if time-saving goods allow a consumer to fully eliminate home labor $\left(\sigma_{s k}=1\right)$, then the classic Corlett and Hague rule applies and time requirements for consumption are irrelevant. ${ }^{18}$

In order to identify the different implications of alternative tax rules, consider the basic commodity "going to the beach," in which being at the beach is assumed to be nontaxable (pure) enjoyable leisure. The individual can either drive to the beach, in which case requires to purchase the market goods "parking at the beach" (there is nothing but beach around) and "gasoline," or can use "public transportation," which is cheaper but requires more time. According to the original Corlett and Hague rule, parking at the beach and public transportation (to the beach), the

\footnotetext{
${ }^{17}$ Of course, when time savings per dollar are equal across goods, then the rule has no effect on optimal tax rates. ${ }^{18}$ As mentioned, Boadway and Gahvari (2006) explicitly made a similar provision when discussing the case of only leisure-substitutes.
} 
goods that are more complementary to leisure, should face tax rates higher than gasoline, which is also used for purposes different than leisure. Gahvari and Yang (1993) and Kleven (2004) would recommend tax rates that are positively related to time intensities, implying that both parking per hour and gasoline (proportional to time used driving) should be taxed at higher rates than under the Corlett and Hague rule, but they should face lower tax rates than public transportation.

In contrast, Boadway and Gahvari (2006) would suggest to tax parking at a positive but relatively low rate, since it is related with pleasant leisure time, while gasoline and public transportation should be taxed at higher rates because they represent unpleasant transportation. This policy would be partially consistent with the time-saving rule proposed in this paper, specifically in what regards to average time savings when income is not very high. For very high-income individuals, time savings are smaller or nil, thus the Corlett and Hague rule is more relevant and the tax on parking should be relatively high. Finally, when marginal time savings are considered, these results can change dramatically. If the effect of taxing parking and gasoline is that lower-income individuals start using public transportation, which requires more time, then it may be optimal to tax those goods at rates lower than other goods in the market - as long as they are used by lower-income individuals.

Since low-income individuals can generally be expected to be more sensitive to changes in tax rates, the reduction in optimal tax rates, or even the optimal subsidies, will be more prevalent among them. It follows that, whenever possible, the optimal commodity tax system should treat differently the goods and services purchased by low- and high-income individuals. Proposition 1 summarizes these results. 


\subsection{Proposition 1: Optimal commodity tax rule.}

If each unit of a basic commodity $z_{j}, j=1, \ldots, J$, is produced with one unit of the market good $x_{j}$, which among all market goods available to produce $z_{j}$ is the one that maximizes its production, and if $x_{j}$ has a market price $p+\pi_{j} \sigma_{s j}+t_{j}$ and a full price $P_{j}=p+\pi_{j} \sigma_{s j}+t_{j}+$ $w\left(1-\sigma_{s j}\right)$, then the commodity tax rule implicit in (11) can be described, for three possible scenarios based on the level of taxpayer's income, as:

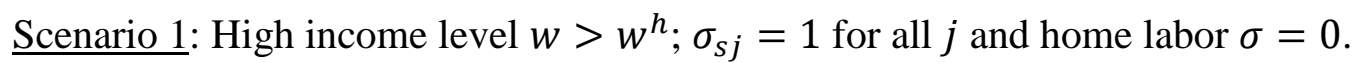

i. The market price and the full price of $x_{j}$ are identical, thus differences in average time savings per dollar do not lead to different tax rates among market goods.

ii. The marginal effect of a tax on the full price of any market good is unity $\left(\partial P_{1} / \partial t_{1}=\right.$ 1), thus the right hand side of (11) is zero and marginal time savings per dollar do not lead to different tax rates among market goods.

iii. Time savings per dollar, in average and in the margin, are irrelevant. Only the Corlett and Hague rule applies in this scenario.

Scenario 2: Intermediate level of income; $0<\sigma_{s j}<1$ for all $j$ and home labor $\sigma>0$.

iv. The market price is lower than the full price of $x_{j}$, thus market goods that provide more time savings per dollar, in average, should be taxed at rates lower than the ones prescribed by the Corlett and Hague rule.

v. The marginal effect of a tax on the full price is greater on market goods that provide greater time savings in the margin. These market goods should be taxed at rates lower than the ones prescribed by the Corlett and Hague rule. 
vi. Time savings per dollar, in average and in the margin, lead to a reduction of the tax rates prescribed by the Corlett and Hague rule.

Scenario 3: Low income level $w<w^{l} ; \sigma_{s j}=0$ for all $j$ and leisure $\rho=0$. Market goods are no longer leisure complements, thus $\varepsilon_{x_{1}, w}^{c}=\varepsilon_{x_{2}, w}^{c}=0$ and the Corlett and Hague rule is irrelevant.

vii. The market price is lower than the full price of $x_{j}$, thus market goods that provide more time savings per dollar, in average, should be taxed at lower rates.

viii. The marginal effect of a tax is zero because $\sigma_{s j}$ is at its minimum value. Marginal time savings per dollar are irrelevant.

ix. Greater average time savings per dollar are associated with lower optimal tax rates.

This proposition assumes, as it is commonly done in the literature, that the market offers a significant number of alternatives to those goods subject to higher taxes. It is apparent, however, that time-saving goods are fewer when the level of income is reduced and, other things equal, that individuals do not voluntarily choose market goods with lower time savings. Instead, the level of income determines the ability to purchase time savings in the market and some individuals, especially those with lower income levels, may be forced to produce basic commodities with a greater share of their own time endowments. In this context, the taxation of home labor should be subject to considerations that are generally disregarded in the literature. If home labor is not enjoyable and does not create income, then even if it is used to produce goods that replace taxed market goods, it is not obvious that it should receive the same tax treatment as leisure and market labor. This position contradicts recent results in the literature. For instance, Kleven (2004) and Boadway and Gahvari (2006) suggest that the solution to the tax problem is first-best when all goods are taxed in accordance to time intensities or all goods are labor- 
substitutes, respectively. In these two cases a first best solution is obtained by applying higher tax rates to goods associated with more home labor. Notably, in line with the conclusion of favoring time-saving goods, Kleven, Richter and Sorensen (2000) suggest to impose lower tax rates on services that are close substitutes of home labor, and Kleven (2004) suggests to favor goods that require little home labor or even save time. However, in both cases the goal is to discourage home labor, which the same as leisure is considered a good that should be taxed but can be easily hidden from the tax authorities. They do not consider the marginal effects of taxes on time savings and thus do not allow for goods requiring more home labor to receive favorable tax treatment in the absence of affordable time-saving substitutes.

The negative effect of taxes on the affordability of time savings can be used as an argument in favor of a tax on luxuries and, more generally, a progressive tax system. To the extent that individuals with different levels of income purchase different time-saving goods, luxury taxes would help to shift the tax burden away from low-income taxpayers. Furthermore, regardless of whether that condition holds or not, the lack of affordable substitutes for lowincome individuals implies that differential tax rates cannot effectively provide them with incentives to reduce home labor. Higher tax rates on goods associated with more home labor may result instead in greater welfare costs of taxation and possibly in zero or even negative marginal tax revenue. This suggests that, in a many-person economy, the optimal revenue requirement associated with low-income individuals should be relatively small. As long as this argument applies to the amount of tax revenue and not to particular market goods, the optimal degree of progressivity can be implemented with the use of the personal income tax. 


\subsection{Homotheticity and weak separability}

Important results of optimal tax theory depend on the assumptions of homotheticity of preferences for goods (or basic commodities), and weak separability of goods and leisure. In the context of the one consumer Ramsey problem, Sandmo (1974) proved that differential commodity taxes are unnecessary when goods and leisure are separable and the subutility of goods is homothetic. The same conclusion about differential taxes was reached by Atkinson and Stiglitz (1976) for the case of a non-linear income tax and weakly separable preferences between leisure and goods. Similarly, Deaton (1979) showed that if, in addition to the separability assumption, Engel curves for goods are linear, optimal commodity taxes can be uniform even when the government is restricted to an (optimal) linear income tax.

These results generally do not hold in the presence of alternative market goods offering costly time savings for the production of a given basic commodity. To see this, note that when income increases, goods providing small time savings become inferior and are eventually replaced by goods that offer greater time savings. This implies that the marginal rate of substitution between any two goods, say between two substitutes providing different time savings, changes with the level of income, and thus preferences cannot be homothetic or display linear Engel curves. Regarding weak separability between leisure and goods, it suffices to consider the two polar (high and low income) cases defined in the previous sections, and to realize that the set of goods consumed with and without leisure will most likely differ.

We can conclude that in the presence of time-saving goods the theory cannot recommend the exclusion of commodity taxes from the optimal solution to the tax problem, and that the optimal commodity tax rule described by Proposition 1 is relevant in the design of that solution. 


\section{Conclusions}

Time-saving goods are very common in the real economy but have not yet received attention in the literature. This paper formally introduces this concept and analyzes the effects of costly time-saving gains on the allocation of time and optimal taxes at different levels of income. Given an exogenous revenue requirement, optimal commodity tax rates should be set in accordance to two rules. The traditional Corlett and Hague rule, by which goods more complementary with leisure should bear a higher tax rate, is especially relevant for high income individuals that spend little or no time on home labor. The time-saving rule derived in this paper, by which goods that save more time per dollar, in average and in the margin, should be assigned a smaller tax rate, is more relevant when income decreases and low income individuals spend more time on home labor. Differential commodity taxation is required to minimize home labor time, especially for low-income individuals.

Two natural extensions to this paper are the empirical analysis of available data on time use and the study of how time inequalities should be addressed by an optimal tax system. Much can be said regarding the appropriate redistributive tax policies in a system that explicitly considers the use of linear or non-linear income taxes and transfers. 


\section{References}

Antonopoulos, Rania; Thomas Masterson and Ajit Zacharias. 2012. "It’s About “Time”: Why Time Deficits Matter for Poverty" Annandale-on-Hudson, NY: Levy Economics Institute of Bard College Public Policy Brief 126.

Atkinson, Anthony Barnes and Joseph E. Stiglitz. 1976. "The Design of Tax Structure: Direct Versus Indirect Taxation." Journal of Public Economics, 6(1-2), pp. 55-75.

Becker, Gary S. 1965. "A Theory of the Allocation of Time." The Economic Journal, 75(299), pp. 493-517.

Boadway, Robin and Firouz Gahvari. 2006. "Optimal Taxation with Consumption Time as a Leisure or Labor Substitute." Journal of Public Economics, 90(10-11), pp. 1851-78.

Corlett, W. J. and D. C. Hague. 1953-1954. "Complementarity and the Excess Burden of Taxation." The Review of Economic Studies, 21(1), pp. 21-30.

Deaton, A. S. 1979. "Optimally Uniform Commodity Taxes." Economics Letters, 2: 357-361.

Gahvari, Firouz. 2007. "On Optimal Commodity Taxes When Consumption Is Time Consuming." Journal of Public Economic Theory, 9(1), pp. 1-27.

Gahvari, Firouz and C.C. Yang. 1993. "Optimal Commodity Taxation and Household Consumption Activities." Public Finance Review, 21(4), pp. 479-87.

Gronau, Reuben. 1977. "Leisure, Home Production, and Work: The Theory of the Allocation of Time Revisited." Journal of Political Economy, 85(6), pp. 1099-123.

Kleven, Henrik Jacobsen. 2004. "Optimum Taxation and the Allocation of Time." Journal of Public Economics, 88(3-4), pp. 545-57.

Kleven, Henrik Jacobsen; Wolfram F. Richter and Peter Birch Sorensen. 2000. "Optimal Taxation with Household Production." Oxford Economic Papers, 52(3), pp. 584-94.

Merz, Joachim and Tim Rathjen. 2014. "Time and Income Poverty: An Interdependent Multidimensional Poverty Approach with German Time Use Diary Data." Review of Income and Wealth, 60(3), pp. 450-79.

Nava, Mario; Fred Schroyen and Maurice Marchand. 1996. "Optimal Fiscal and Public Expenditure Policy in a Two-Class Economy." Journal of Public Economics, 61(1), pp. 119-37.

Sandmo, Agnar. 1974. "A note on the Structure of Optimal Taxation." American Economic Review, 64(4), pp. 701-706.

Sandmo, Agnar. 1990. "Tax Distortions and Household Production." Oxford Economic Papers, 42(1), pp. 78-90. 
Vickery, Clair. 1977. "The Time-Poor: A New Look at Poverty." The Journal of Human Resources, 12(1), pp. 27-48.

Zacharias, Ajit. 2011. "The Measurement of Time and Income Poverty." Annandale-on-Hudson, NY: Levy Economics Institute of Bard College Working Paper 690. 